\title{
A NOÇÃO DE CAMPO APLICADO À JOALHERIA.
}

\author{
Ana Neuza Botelho Videla \\ Estudante de doutorado em Design -UFPE, professora assistente da UFCA. \\ e-mail: videla.ana@gmail.com \\ Kátia Medeiros de Araújo \\ Professora Dra. Universidade Federal de Pernambuco - UFPE \\ e-mail: katia_araujo@hotmail.com.br
}

\begin{abstract}
Resumo: A joalheria é um campo composto por algumas categorias, como: joalheria industrial, design-joalheria, joalheria de autor, joalheria de estúdio, arte-joalheria. Algumas destas categorias sofrem mais influência do mercado, enquanto outras são influenciadas por tendências que vem do campo da arte. A partir do conceito de campo de Bourdieu - o qual pode ser compreendido como o espaço estruturado, onde seus membros, os indivíduos e instituições, competem pelo monopólio sobre uma determinada produção cultural - propõe-se uma reflexão sobre as circunstâncias que ocasionaram a mudança nas regras do jogo, levando os empresários joalheiros a exigir do profissional ingressante na área de configuração de joias uma formação específica em design. Assim, de acordo com a abordagem bourdieusiana, a luta pela hegemonia de um arbitrário cultural, nesse momento, gira em torno da consolidação do campo da joalheria com a incorporação das práticas do campo do design.
\end{abstract}

Palavras-chave: Joalheria, design, campo, sociologia.

Abstract: The jewelry is a field that consists of a few categories, such as: industrial jewelry, jewelry design, jewelry copyright, studio jewelry, jewelry art. Some of these categories suffer more market influence, while others are influenced by trends coming from the field of art. From the concept of Bourdieu's field - which can be understood as a structured space where its members, individuals and institutions compete for monopoly on a particular cultural production - we propose a reflection on the circumstances that led to the change in rules of the game, leading jewelers entrepreneurs require professional entrant in the configuration area of specific training in jewelry design. Therefore, according to Bourdieu's approach, the struggle for hegemony of a cultural arbitrary at this point, revolves around the consolidation of the field of jewelry incorporating the practices of the field of design

Keywords: jewelry, design, field, sociology. 


\section{INTRODUÇÃO}

A proposta deste trabalho é apresentar as categorias que compõem a Joalheria, levando-se em consideração tendências que vem do mercado e tendências que vem do campo da arte, a fim de analisar a maneira como o design foi incorporado na joalheria, tendo em vista o conceito bourdiesiano de campo. Para isso, faz-se necessário uma breve apresentação da Joalheria e algumas de suas categorias. Embora a Joalheria, ou mais precisamente, a ornamentação corporal, seja uma das atividades mais antigas já praticadas pelo homem, e esteja presente em todas as formas de organização social, a joalheria que se analisará aqui é a ocupação profissional desenvolvida nos dias atuais. Mais ainda, a atividade que se pretende enfatizar é a constituição do campo da joalheria sob a influência do design.

Vale ressaltar que o campo da joalheria é alvo de influências externas, dos campos do design e da arte. Isto é, o campo é o tempo todo crivado por questões e concepções que tem uma procedência exterior, através do qual entrevemos a luta pela consagração de um "arbitrário cultural", pois de acordo com essa abordagem sociológica, não é possível conceber nichos relativamente independentes, cada um dos quais movidos por concepções diferentes do que seja joalheria. Se assim fosse, de acordo com a correta terminologia utilizada por Bourdieu, teríamos que conceber cada um desses nichos como campos autônomos. Segundo o autor, teríamos que pensar, antes, o campo da joalheria enredado em uma luta pelo monopólio da consolidação, em cada momento, por uma concepção de joalheria. Ou seja, os efeitos dos outros campos, ou entrelugar da Joalheria, entre a arte e o design, repercute do ponto de vista das lutas internas do campo, das lutas pelo monopólio da capacidade de dizer o que é joia.

De acordo com Wacquant (2005, p. 117), a noção de campo artístico mostra um "espaço estruturado de posições e tomadas de posição, onde os indivíduos e instituições competem pelo monopólio sobre a autoridade artística à medida que esta se autonomiza dos poderes econômicas, políticos e burocráticos". O que o autor quer dizer com a autonomia do campo para além das outras dimensões, é que o critério estético se sobrepõe de acordo com o princípio predominante da percepção artística. Ao transpor a noção de campo para a Joalheria, poderíamos nos referir à luta empreendida pelos membros do campo para obter o monopólio de engendrar um arbitrário cultural que lhes interessa. Vale ressaltar que essas lutas não são desinteressadas, estar na posição hegemônica implica em ganhos. Segundo Bourdieu, "Esses conflitos são o motor da história específica do campo: a luta é o "princípio generativo e unificador" através do qual este se temporaliza e se abstrai, em certa medida, de determinações envolventes" (Bourdieu apud Wacquant, 1992, p. 199). Quer dizer, por meio das lutas é que se consolida uma posição. O entrelugar da joalheria abre espaço no seu interior para posições que estão mais próximas do design e posições que estão mais próximas do mundo da arte. Por ser um campo sujeito a influências de fatores externos, sua autonomia pode ser relativa.

Portanto, para Bourdieu, o campo cultural é unificado sob o domínio de uma doxa, assim, para exercitar o seu pensamento, o campo da joalheria teria em cada momento um "arbitrário cultural" legítimo. Nesta perspectiva, a questão que aqui se coloca seria discutir até que ponto ocorre a violência em torno da unificação de um "arbitrário cultural" legítimo no campo da Joalheria ou, a partir de que momento ele passa por uma decadência e, a partir de que momento outro "arbitrário cultural" passa 
a se solidificar, por exemplo. É possível se pensar em um arbitrário hegemônico na joalheria? Como ele se constitui? Se essa hegemonia é construída, como se construiu um arbitrário hegemônico em torno da joia?

A metodologia empregada para esse estudo foi a revisão bibliográfica e entrevistas com alguns membros do campo. Como o objetivo deste artigo é conhecer como foi constituída a concepção da joalheria influenciada pelo design, empregamos os dados obtidos através de documentos do setor joalheiro, criado pela associação de classe e bibliografia sobre o campo, mesmo material utilizado na pesquisa do doutorado em curso.

\section{DESENVOLVIMENTO}

A joalheria é uma atividade com uma série de denominações, algumas dessas denominações estão mais relacionadas à função de ornamentação corporal, como a alta joalheria, a joalheria industrial, joalheria ligada à moda ou ao design, de um lado, e, no outro extremo, encontramos as categorias que problematizam a joia como ornamentação, como é o caso da arte joalheria.

Assim, iniciaremos a apresentação da joalheria pela alta joalheria, cujo propósito é produzir peças de luxo. Isso significa que para produzir peças dessa categoria se enfatiza, sobretudo, dois elementos, matéria-prima rara e nobre e mãode-obra altamente qualificada e extremamente habilidosa. As matérias-primas utilizadas nestas peças são, sobretudo, as ligas, que é a combinação de dois ou mais metais, e as gemas ${ }^{1}$ com características naturais especiais. A produção de uma peça de alta joalheria exige um alto grau de perfeição, evidentemente que outras características são importantes, como o design e as inovações tecnológicas, no entanto, os dois itens destacados são os mais emblemáticos para essa categoria. Mais uma vez, destacaríamos na produção da peça de luxo esses dois itens, a dobradinha dos aspectos naturais/tecnológicos, da preparação das gemas e ligas e os recursos humanos da execução perfeita da joia.

Se pensarmos o conceito bourdiesiano de campo para essa categoria da joalheria, artefatos produzidos por marcas como a Chanel, Bvlgari, Christian Dior, podemos observar que funciona como um demarcador de classe ainda mais predisposto a exprimir as diferenças sociais. O consumidor de uma peça de luxo é portador de um capital simbólico altamente distintivo. Quer dizer, esse consumidor possui um bem que o distingue por pertencer a uma fração dominante da classe dominante. O consumo de uma peça de alta joalheria exige não só possuir um alto capital econômico, como um conhecimento especial em gemas e algum conhecimento técnico, os quais implicam numa competência cultural específica necessária para que ocorra a apropriação destes objetos. Significa dizer que, ao consumir uma peça desta categoria é preciso possuir tanto capital econômico, como capital cultural, daí se poder afirmar que o consumidor da joalheria de luxo pertence à fração dominante da classe dominante.

Joalheria de autor, joalheria contemporânea e arte joalheria são denominações adotadas sem muita precisão, embora se possa afirmar que são categorias que se contrapõem à joalheria industrial ou ao modelo que é praticado com intuito de obter escala. Neste sentido, a historiadora da arte Liesbeth den Besten define uma série de

\footnotetext{
${ }^{1}$ O sentido da palavra "gemas" é derivado da gemologia, significa pedras preciosas.
} 
categorias da Joalheria, tais como: joalheria contemporânea, joalheria de estúdio, arte joalheria, joalheria de pesquisa, design joalheria e joalheria de autor (Den BESTEN, 2011, p: 9 - 11). As categorias com expressão artística, como a arte joalheria, sofrem influência do campo da arte. No entanto, é esse entrelugar da joalheria, entre o design e a arte, que pode dificultar a unificação da doxa, ou de uma concepção dominante e hegemônica da atividade e, por conseguinte, revelar os limites do conceito de campo para analise do objeto em questão. A não ser que o conhecimento específico da joalheria, ou para utilizar os termos bourdiesianos, o capital joalheiro opere a mediação entre o campo e o conhecimento exógeno. Isto é, podemos conceber a idéia da constituição de um campo da joalheria, na medida em que se identifica o capital joalheiro. Por capital joalheiro se entende o conhecimento específico da joalheria, dos materiais, técnicas, das formas de comercialização e produção acumuladas através da história adquirida pela antiguidade da posição.

Portanto, o conceito de campo pode auxiliar na analise mais internalista da joalheria, na medida em que permite a compreensão da atuação das diferentes categorias que compõem a joalheria e as disputa que aí são engendradas. Vai ser através do espaço de disputa que se determina as lutas e o que elas visam manter ou redefinir. Assim, é a lógica do campo que vai estabelecer as propriedades da relação entre classe e prática, ou classe e preferências de gosto. Nesta perspectiva, a correlação se dá entre "gostos com as condições econômicas e sociais, por um lado, e, por outro, os produtos que por intermédio desses gostos, recebem suas diferentes identidades sociais" (BOURDIEU, 2013, p. 95).

Ainda segundo Bourdieu, a homologia, que trata da correspondência entre a produção e os gostos, ou entre demanda e oferta, como o resultado da orquestração objetiva de duas lógicas relativamente independentes, a da produção e a do consumo, quando transposto para a Joalheria, pode levar ao extremo o potencial do instrumental teórico (Idem, p. 215 - 216). De acordo com o autor, a luta entre a concorrência e o surgimento de novos produtos, forma de imposição simbólica, é responsável pela mudança de gosto do consumidor. "O campo da produção [...] é que permite o gosto de se realizar ao oferecer-lhe a cada instante, o universo de bens como sistema de possibilidades [...]" (Idem). Em termos gerais, os gostos vão se estabelecendo através da identificação com os produtos ou serviços adequados à sua posição social e condicionados com o que é ofertado. Além disso, nos campos mais autônomos, os indivíduos recebem ajuda na formação do gosto, através dos críticos, consultores, jornalistas, escolhidos de acordo com a mesma lógica da homologia dos campos especializados. Isto é, esses especialistas, como membros do campo, reforçam e defendem em suas opiniões as suas posições sociais. Para Bourdieu, esses diferentes campos atuam de acordo com a mesma lógica, ou seja, uma luta entre os dominantes, os quais possuem mais volume de capital específico e antiguidade do seu posicionamento, e os que querem conquistar espaços e se estabelecer no campo. Dessa forma, Bourdieu fala de uma homologia entre bens e grupos, onde há uma transferência de capitais simbólicos entre indivíduos situados em posições homólogas nos diferentes campos; de modo que, são as homologias que geram essas cumplicidades entre os produtores e seus clientes (Idem, p. 225). Vale ressaltar, que no âmbito da produção, foco deste estudo, a luta que se estabelece já é entre grupos que compõem o campo, por assim dizer, entre joalheiros artesanais, designers das 
empresas maiores, designers autônomos, industriais do setor, joalheiros de ateliês, artistas joalheiros, etc.

\subsection{Quando a joalheria é design}

Como na Joalheria há uma grande diversidade de categorias, algumas muito destoantes entre si, as quais são pautadas por práticas que vão das mais artesanais às mais industriais, qual seria o pretexto da luta no campo da joalheria?

Com o intuito de conhecer a constituição de um arbitrário hegemônico na joalheria e buscar compreender algumas indagações aqui colocadas, a proposta é promover uma breve análise de um período recente - de 2004 a 2010 - por ter sido rico em debates, em ações políticas por parte dos empresários e de instituições governamentais, como a constituição de APLs de Joias (Arranjos Produtivos Locais de Joias) em alguns Estados do país e o apoio do Ministério do Desenvolvimento, Indústria e Comércio Exterior (MDIC), do qual gerou uma série de movimentos em defesa do uso das matérias-primas e produtos brasileiros nas joias, culminando no documento "Políticas e Ações para a Cadeia Produtiva de Gemas e Joias", publicado em 2005. Dito isto, a seguir, analisaremos a categoria da joalheria industrial que desde o início dos anos 2000 teve efeito o princípio de uma luta política, na qual envolveu vários representantes do setor joalheiro, entre eles, sindicatos e órgãos públicos, a fim de estabelecer mais espaço para o campo da Joalheria.

A joalheria industrial é, dentre as categorias que compõem o campo da joalheria, a categoria que pode trabalhar com escala ${ }^{2}$. Assim, a depender do nicho que a empresa escolhe atuar, é possível agilizar e otimizar boa parte da produção, no sentido de eliminar ao máximo as etapas artesanais de montagem das peças e os processos de acabamentos manuais, os quais passam da bancada do ourives para procedimentos automatizados da produção. A fabricação continua a ter uma predominância de materiais nobres, mas a joalheria industrial adota combinações com outros materiais, como madeira, couro, esmaltes, aço e titânio, etc. Para essa categoria de joalheria, tanto o design, como o processo produtivo visam agilizar o aumento da produção e, por conseguinte, o lucro. Nesse sentido, é importante destacar que ao se pensar em design e processo produtivo, está-se incluído etapas de um processo maior. Segundo a pesquisa realizada por Walsh (1996, p. 521), as empresas adotam uma grande variedade de significados para design. Entretanto, para uma visão mais ampliada da atividade de design, mais relacionada à gestão da atividade, o sentido é de construir vínculos entre as várias funções das empresas e seus ambientes, daí não fazer sentido separar a área de configuração ou projeto, do processo produtivo, quando o objetivo da empresa é um só, atingir os melhores resultados nos negócios.

2 Disponível na internet por http em:

http://www.colenindustrial.com.br/website/?menu=Not\%EDcias\&titulo=VicenzaOro\%202012\%20-

\%200lhares\%20sobre\%200\%20futuro\%20inevit\%E1vel\&id=6 Acesso em 28 de dez. de 2013. Os equipamentos utilizados na indústria joalheira têm por objetivo maximizar a produção. Um exemplo são as pré-cravações nos modelos em ceras, os quais são preparados para serem fundidos em altas temperaturas. Essa técnica acelera o processo de cravação, pois as peças já saem da fundição com as gemas, o cravador apenas dá os arremates finais. 
Através das ações do IBGM (Instituto Brasileiro de Gemas e Metais Preciosos), podemos dizer que nos últimos quinze anos, aproximadamente, o design, paulatinamente, passou a contribuir para melhorar a performance de empresas no Brasil. Mas para que esses resultados pudessem aparecer, foi necessária uma série de ações cujo intuito foi fazer com que as empresas joalheiras passassem a incorporar o design nas suas práticas. Em decorrência do levantamento de informação sobre o campo joalheiro para a elaboração do documento supracitado, identificou-se, entre outras coisas, a escassez tecnológica do setor joalheiro, bem como a fragilidade, ou mais precisamente, a quase inexistência do reconhecimento da necessidade de incorporação do design para o setor de joias. Como a grande maioria das empresas joalherias ${ }^{3}, 96 \%$ delas são formadas por micro e pequenas empresas, o empresário desse segmento tem que atuar um pouco em todas as áreas, e nesse contexto, muitas vezes era mais valorizado um modelista ${ }^{4}$, do que um designer.

O trabalho desenvolvido pelas associações de classe foi no sentido de convencer os empresários da indústria joalheira da importância em investir em design, ao mesmo tempo, desenvolveram ações de marketing a fim de valorizar o design brasileiro no exterior. Segundo a impressa especializada, essas ações deram resultados, sendo a crescente valorização do design de joias brasileiro, a mudança mais significativa. Em um curto período, por volta de dez anos, de acordo com os blogs especializados e das associações de classe, o design de joias brasileiro passou por uma brusca transformação, foi de copista até uma avaliação mais positiva. Dessa forma, uma das ações com bastante visibilidade foram os concursos de design de joias, que o IBGM passou a lançar a partir de 1995. Durante um longo período a opção dos empresários era contratar artistas ou autodidatas para a criação de joias, uma ação, muitas vezes, combinada com a cópia de peças de revistas estrangeiras, pois eles não consideravam que a joia resultasse de um projeto de design. É importante assinalar, que a inserção do design foi uma ação política, promovida, sobretudo, pelas associações de classe. Assim, nesse período, vemos as regras do jogo sofrerem uma clara mudança, uma vez que paulatinamente os empresários passaram a exigir do profissional ingressante na área de configuração de joias uma formação específica em design. Ou seja, em termos bourdieusiano a luta para a hegemonia de um arbitrário, nesse momento, é para consolidar o campo da joalheria com a incorporação de práticas do campo do design. $O$ design é fonte da racionalização da atividade típica de todo campo, o qual é incorporado ao domínio técnico e sobre o que é o objeto do campo. Embora as regras de autonormatização estejam em curso, as mudanças estão em vias de consolidação, pois para transformar a cultura da empresa é preciso tempo para introjetar novas práticas.

Conforme mencionado anteriormente, em 2005, o Ministério do Desenvolvimento, Indústria e Comércio Exterior (MDIC) em parceria com o IBGM, publicaram "Políticas e ações para a cadeia produtiva de gemas e joias". Em termos muito gerais, o Brasil ainda exporta muita matéria-prima, com isso o país deixa de gerar emprego, riqueza e divisas. Ou seja, chegou a ser uma medida de política

3 Disponível na internet por http://www.ibgm.com.br/admin/_upload/estatistica/arquivo/671OSetoremGrandesNumeros2012_Completo.pdf Acesso em 27/12/2013

${ }^{4} \mathrm{O}$ modelista é o profissional que prepara o modelo e encontra as soluções técnicas que serão adotadas na produção da joia. 
pública, pois a iniciativa era no sentido de modificar esse quadro, não apenas exportar matéria-prima, gemas e metais, mas passar a beneficiá-los e agregá-los às joias.

O incentivo dos órgãos governamentais não pode deixar de ser mencionado, principalmente através do Ministério do Desenvolvimento, Indústria e Comércio Exterior - MDIC, possivelmente essa situação se deve à identificação do potencial promissor que o campo joalheiro tem para se desenvolver, sobretudo por contar com uma situação privilegiada em termos de matéria-prima. Em suma, poderíamos sugerir que a consolidação da concepção de joalheria, para os representantes do setor, implicaria na incorporação do design. Ou seja, todo o esforço do campo joalheiro foi no sentido de se aproximar do design, modernizar as empresas, torná-las mais competitivas em termos de tecnologia para gerar inovação, a fim de alavancar as exportações. Assim, vemos o Estado tentando transformar e erradicar os obstáculos que dificultam a consolidação e crescimento desse campo, visto que foi identificado o potencial de crescimento da joalheria industrial. Dessa forma, políticas foram estabelecidas visando criar condições para o desenvolvimento do campo.

\section{CONCLUSÃO}

Ao reconstruir as diferentes posições no interior do campo, levando em consideração tendências que vem do mercado e indicando tendências que vem do campo da arte, a fim de ver como tudo isso se articula, o intuito foi conceber a composição da joalheria através da coexistência das diversas categorias que fazem parte da estrutura interna do campo e, ao mesmo tempo, identificar o pretexto da luta pela hegemonia da concepção do que é joia. Conforme mencionado, na joalheria comercial o campo de maior repercussão é o design, e o seu processo tem uma lógica própria, que não dá para ser aplicado ao pensamento e instrumental da arte, que por sua vez age com mais intensidade em outras categorias da joalheria.

Entretanto, é interessante observar que o design também já apresentou resistência em aceitar a joia no seu escopo de práticas, sobretudo por identificar nestes artefatos uma falta de função, no caso específico do design a crítica à joia se dava mais pela frivolidade do artefato, se argumentava que na joia não havia uma função social. Vale observar, que essa mesma característica, denominado negativamente pelo design, por falta, é alvo da crítica das instâncias de consagração da arte, por ter uma criação orientada para o corpo. Ou seja, dependendo do campo, o mesmo aspecto pode ser observado por possuírem sentidos opostos. Outras características, como a produção artesanal, dificuldade de reprodução em escala ou a ornamentação, podem distanciar esse campo, tanto da arte, como do design. Todas essas características só reforçam a relativa autonomia do campo da Joalheria.

Embora, estejamos falando de um campo, nos parece que os elementos de autonormatividade são distintos, ou seja, a joalheria comercial, após as lutas políticas impetradas por suas instituições de consagração, passou a ter no design o campo com maior intervenção, e, por outro lado, a arte joalheria busca criar estratégias para se aproximar do campo da arte. Isto é, se é verdade que os dois campos possuem regras e pressuposto bem distintos, onde um não serve para ser aplicado no entendimento do outro, em que medida o entrelugar da Joalheria nos permite falar de campo? 


\section{REFERÊNCIAS}

BESTEN, Liesbeth den. On Jewellery - a compendium of international contemporary art jewellery. Stuttgart:Arnoldsche Art Publishers, 2011.

BOURDIEU, Pierre. "La metamorfosis de los gustos". In Cuestiones de Sociología. Madrid: Ediciones Istmo, 2011

A distinção - crítica social do julgamento. 2. ed. rev. 1. reimpr. Porto Alegre: Zouk, 2013.

IBGM. Instituto Brasileiro de Gemas e Metais Preciosos. Políticas e Ações para a Cadeia Produtiva de Gemas e Jóias. Disponível na internet por http em: http://www.ibgm.com.br/. Acesso em 28 dez. 2013.

WACQUANT, Loic. "Mapear o campo artístico". Sociologia, problemas e práticas. Lisboa: número 48, 2005, pp. 115-121.

WALSH, Vivien. Design, Innovationand the boundaries of the firm. Manchester.

ELSEVIER. Research Policy 25/509-529. 1996. 